\title{
Theoretical and Experimental Results of Substrate Effects on Microstrip Power Divider Designs
}

\author{
Suhair Mansoor Mahmood ${ }^{1}$ and Asaad M. Jassim Al-Hindawi ${ }^{2}$ \\ ${ }^{1}$ Space Technology Department, Science and Technology Ministry, Baghdad 1125, Iraq \\ ${ }^{2}$ Electrical and Electronic Department, Sulaimani Technical College, Sulaimani 2972, Iraq
}

Correspondence should be addressed to Suhair Mansoor Mahmood, suhair40@hotmail.com

Received 2 May 2011; Revised 7 July 2011; Accepted 7 July 2011

Academic Editor: Ning Hua Zhu

Copyright (c) 2011 S. Mansoor Mahmood and A. M. Jassim Al-Hindawi. This is an open access article distributed under the Creative Commons Attribution License, which permits unrestricted use, distribution, and reproduction in any medium, provided the original work is properly cited.

\begin{abstract}
The effects of substrate materials on the design of microstrip power divider are investigated theoretically and experimentally. Three dielectric substrate materials, Duroid 3003, G10/FR4 epoxy Glass, and Duroid 3010, are chosen to be studied. A three-way twostage power divider is designed at S-band frequency of $2.25 \mathrm{GHz}$ and etched on each studied substrate separately. The substrate effects on the characteristics and performance of the microsrip circuits are studied taking into consideration the large difference in dielectric constant and the dissipation factor. The circuit designs presented here are analyzed using the Genesys CAD program and implemented and tested experimentally. The simulated and measured results are compared and discussed, and they indicate that significant changes in the characteristics of the microstrip power divider are observed.
\end{abstract}

\section{Introduction}

The power divider technology has undergone a substantial change over the past decade, due to smaller size, lighter weight, potentially lower cost, high reliability, broad bandwidth capability, and function reproducibility $[1,2]$. When selecting a suitable substrate material, factors to be considered in the designs of the microstrip power dividers are cost, availability, ease of machining, and etching. There are a whole range of mechanical, electrical, thermal, and chemical criteria to be taken into account $[3,4]$. Most of these criteria are mechanical stability with high and low storage temperature, thermal expansion similar to that of metals, good electrical properties (homogeneity of $\varepsilon_{r}$ and high electric insulation strength), chemical resistance and easy workablity with low cost [3]. There is no substrate material that simultaneously fulfils all the above requirements. The best compromise must be found for all applications [5]. The materials commonly used for microwave substrate have dielectric constants typically range from 2.0 to 10.0. Microstrip circuits designed to be fabricated on such dielectric materials will be most compact or pressed because of the wave-slowing action of the electric signal. Usually, this is an advantage,

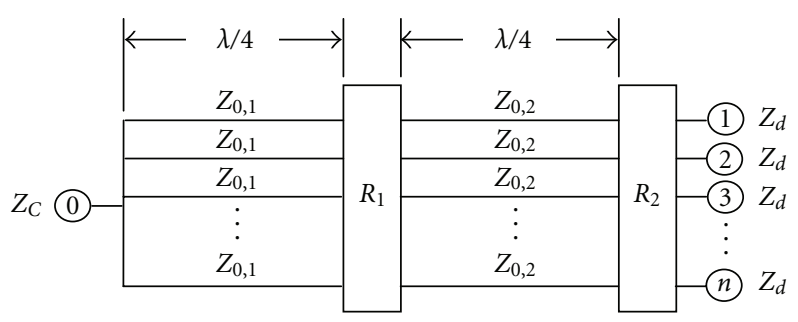

FIGURE 1: Schematic representation of two-stage power divider.

but such small size makes it difficult to fit any conventional discrete parts into microstrip layout. There are Teflon/ceramic mixture with lower dielectric constants, such as 6.0 , which produce physical layer microstrip layout; this helps to alleviate the components mounting problem [6].

The present study investigates the effects of the dielectric substrate materials on the design of microstrip power dividers on which they are etched. Duroid 3003, G10/FR4 epoxy glass, and Duroid 3010 substrates are chosen to be studied. The effects of the differences in the dielectric constants and the dissipation factors on circuit design are included. 
(1)

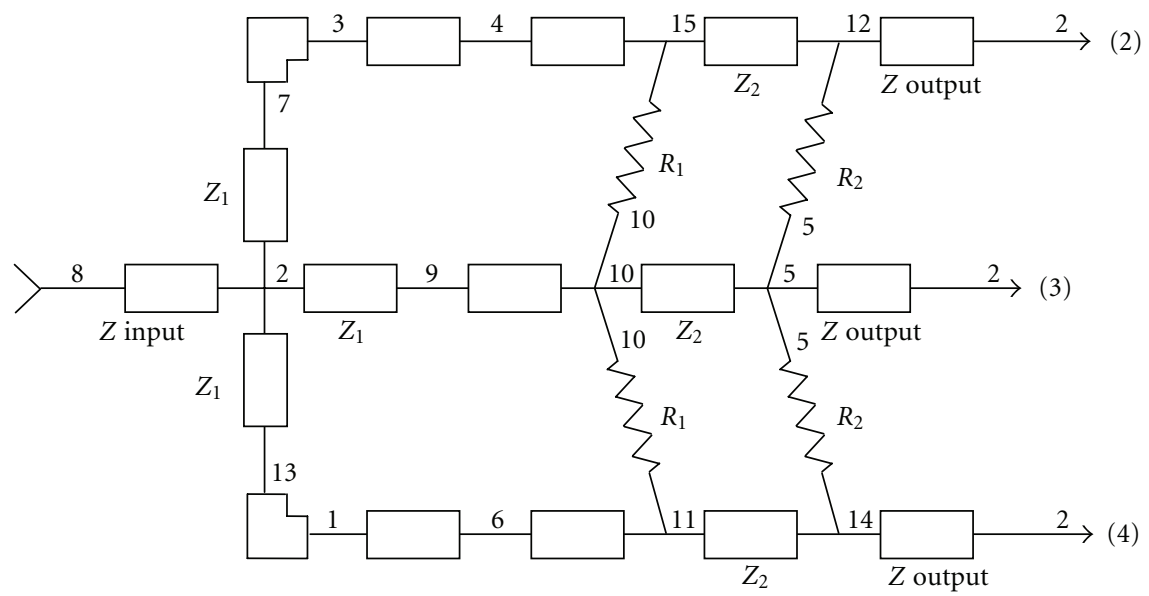

FIGURE 2: Schematic diagram of 3-way 2-stage power divider designed on Duroid 3003.

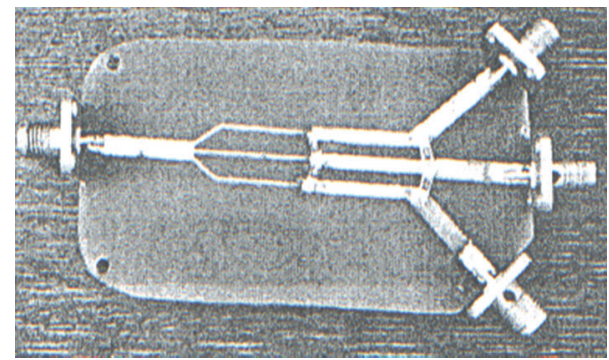

FIGURE 3: Picture of 3-way 2-stage power divider etched on Duroid 3003 board (Dim. $100 \mathrm{~mm} \times 55 \mathrm{~mm}$ ).

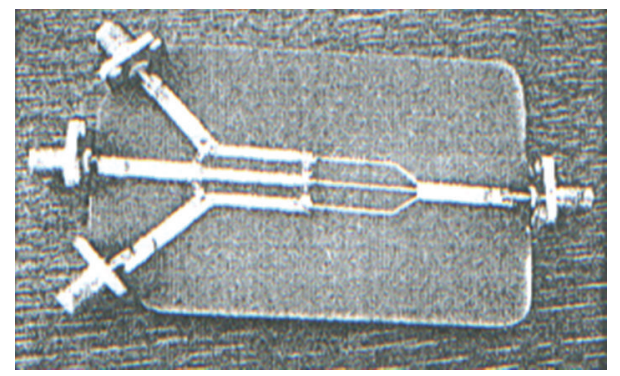

Figure 4: Picture of 3-way 2-stage power divider etched on epoxy glass board (Dim. $93 \mathrm{~mm} \times 49 \mathrm{~mm}$ ).

\section{Microstrip Power Divider Designs}

A schematic diagram of the two-stage Wilkinson N-way divider is shown in Figure 1.

The common port is designated the number 0 and is assumed to be terminated in $Z_{c}$. The divider ports are designated the number 1 through $N$, and each is terminated in $Z_{d}$. The characteristic impedance of each quarter-wave line is $Z_{0,1}$ and $Z_{0,2}$ while the isolation resistors are designated $R_{1}$ and $R_{2}$. The justification for the coupling among all transmission lines beyond the first stage of the divider is that such lines would be reasonably separated from one another [7]. Also the junction effects will be neglected. It will be assumed
TABLe 1: Optimum resistors of two-stage $\mathrm{N}$-way power divider [7].

\begin{tabular}{lcc}
\hline$N$ & {$\left[R_{1} Z_{d} / Z_{0,2}\right]_{\mathrm{opt}}$} & $\left(Z_{d} / R_{2}\right)_{\mathrm{opt}}$ \\
\hline 2 & 1.28719 & 0.17828 \\
3 & 0.75000 & 0.25000 \\
4 & 0.50000 & 0.25000 \\
5 & 0.39991 & 0.33609 \\
6 & 0.36676 & 0.36285 \\
7 & 0.39652 & 0.35000 \\
8 & 0.52493 & 0.30118 \\
10 & 0.52482 & 0.30121 \\
12 & 0.52483 & 0.30120 \\
\hline
\end{tabular}

that port 0 (input port) is perfectly matched at the center frequency. Thus, for two-stage hybrid

$$
Z_{0,1}=Z_{0,2}\left(\frac{N Z_{c}}{Z_{d}}\right)^{1 / 2}
$$

where $Z_{c}$ and $Z_{d}$ are the input and output impedances of the power divider, respectively. For a maximally flat inputoutput frequency response, the following impedances are

$$
\begin{aligned}
& Z_{0,1}=\left(N Z_{c}\right)^{3 / 4}\left(Z_{d}\right)^{1 / 4}, \\
& Z_{0,2}=\left(N Z_{c}\right)^{1 / 4}\left(Z_{d}\right)^{3 / 4} .
\end{aligned}
$$

The addition of input and output transformers to improve the frequency response is allowed provided that (1) is satisfied with $Z_{c}$ and $Z_{d}$ referred to terminals of the dividers [7]. Table 1 represents the optimum resistor of two-stage Nway power divider [7]. 


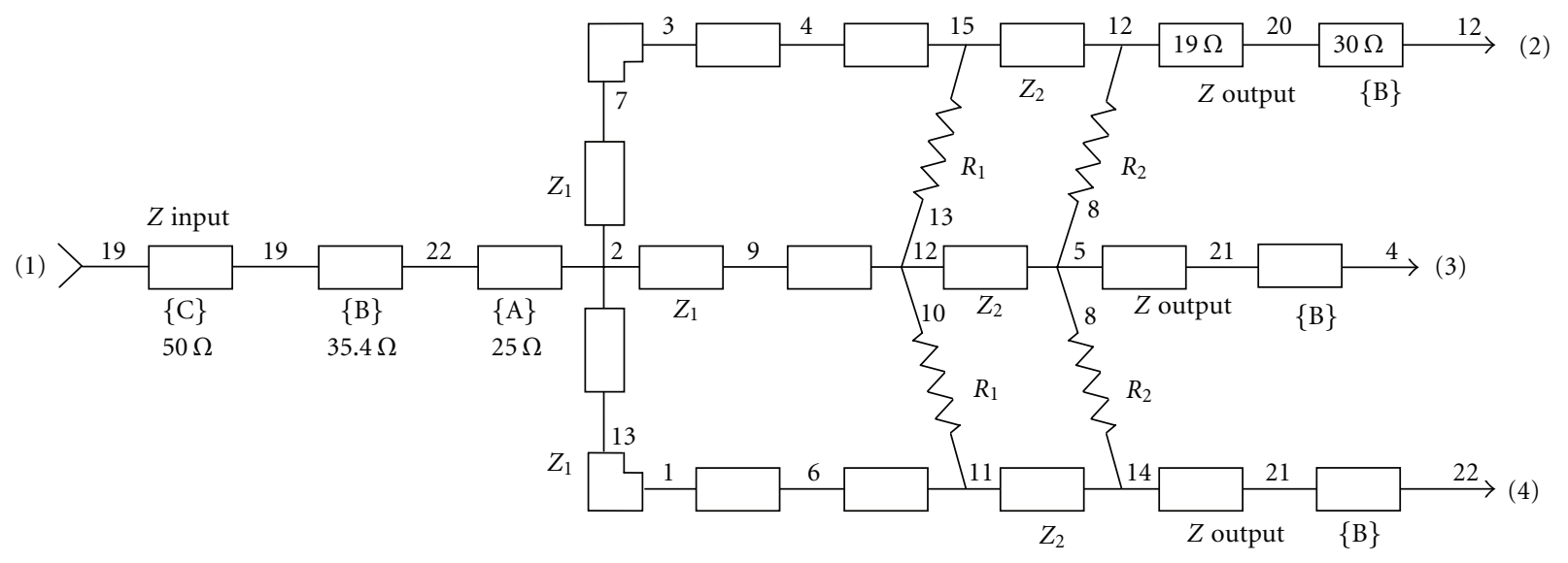

FIGURE 5: Schematic diagram of 3-way 2-stage power divider designed on Duroid 3010.

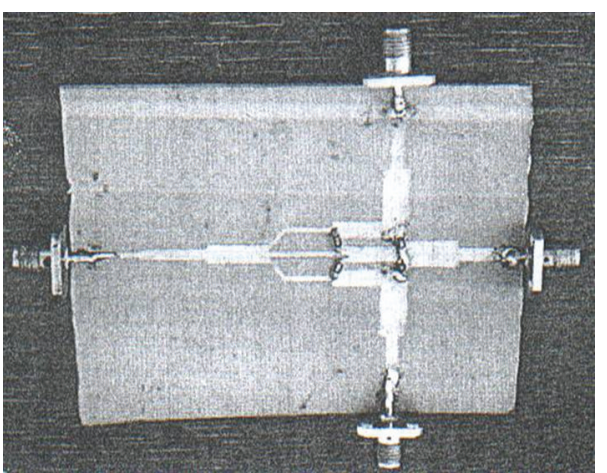

FIGURE 6: Picture of 3-way 2-stage power divider etched on Duroid 3010 board (Dim. $110 \mathrm{~mm} \times 90 \mathrm{~mm}$ ).

The characteristic impedance of the microstrip line $Z_{0 L}$ may be expressed in terms of line width $w$ and substrate thickness $h$, and effective dielectric constant $\varepsilon_{e}$ as [4]

$Z_{0 L}=\left\{\begin{array}{cc}\frac{60}{\sqrt{\varepsilon_{e}}} \ln \left(\frac{8 h}{w}+\frac{w}{4 h}\right) & \text { for } \frac{w}{h} \leq 1 \\ {[120 \pi]\left[\sqrt{\varepsilon_{e}}\left(\frac{w}{h}+1.393+0.677\right.\right.} & \\ \left.\left.\times \ln \left(\frac{w}{h}+1.44\right)\right)\right]^{-1} & \text { for } \frac{w}{h}>1\end{array}\right\}$,

where

$$
\varepsilon_{e}=\frac{\varepsilon_{r}+1}{2}+\frac{\varepsilon_{r}-1}{2}\left(1+\frac{12 h}{w}\right)^{-1 / 2}
$$

and $\varepsilon_{r}$ represents relative dielectric constant of the substrate. The dielectric loss $\alpha_{d}$ is given by [4]

$$
\alpha_{d}=\frac{\pi}{\lambda_{0}} q \tan \delta, \quad N_{p} / m,
$$

where $q=\left(\varepsilon_{r}\left(\varepsilon_{e}-1\right) / \varepsilon_{e}\left(\varepsilon_{r}-1\right)\right)$ and $\tan \delta$ represents dissipation factor.
TABLE 2: Specifications of the studied substrates with the dimensions of quarter wavelength line $(50 \mathrm{ohms})$ for each.

\begin{tabular}{lccc}
\hline & Duroid 3003 & Epoxy glass & Duroid 3010 \\
\hline Dielectric constant $\varepsilon_{r}$ & 3 & 4.4 & 10.2 \\
Dielectric thickness $h$ & $1.52 \mathrm{~mm}$ & $1.6 \mathrm{~mm}$ & $1.25 \mathrm{~mm}$ \\
$\begin{array}{l}\text { Dissipation factor } \\
\text { Width of quarter }\end{array}$ & 0.0013 & 0.013 & 0.0035 \\
$\begin{array}{l}\text { wavelength line } \\
\text { Length of quarter }\end{array}$ & $3.84 \mathrm{~mm}$ & $2.47 \mathrm{~mm}$ & $1.10 \mathrm{~mm}$ \\
wavelength line & $21.91 \mathrm{~mm}$ & $18.42 \mathrm{~mm}$ & $12.71 \mathrm{~mm}$ \\
\hline
\end{tabular}

Table 2 illustrates the specifications of the studied substrate materials with the dimensions of $50 \mathrm{ohms}$ line for each one.

2.1. Power Divider with Duroid 3003 and Epoxy Glass Substrates. A $50 \mathrm{ohms}, \lambda_{g} / 4$ line at midband frequency of $2.25 \mathrm{GHz}$ is $3.84 \mathrm{~mm}$ wide, $21,91 \mathrm{~mm}$ long for the Duroid 3003 substrate and $2.47 \mathrm{~mm}$ wide, $18.42 \mathrm{~mm}$ long for epoxy glass substrate. The main difference between these two substrates is the dissipation factor $(\tan \delta)$. They are near in the dielectric constants and the thickness of the substrate, therefore the layout design is changed in the range of a few millimeters. The dissipation factor does not affect the dimensions of the power divider design, its effect will be clear in the simulated and practical response curves.

Using (2), the impedance design values are $Z_{0,1}=$ $113.975 \Omega, Z_{0,2}=65.803 \Omega, R_{1}=64.954 \Omega$, and $R_{2}=200 \Omega$, with the input and the output impedances set at $Z_{1 n}=Z_{\text {out }}=$ $Z_{d}=Z_{c}=50 \Omega$.

Figure 2 shows the schematic diagram of power divider designed on Duroid 3003 or epoxy glass substrate noticing that only the slight differences in the dimensions of the microstrip lines related to the change in dielectric constant and thickness of the used board.

Figures 3 and 4 illustrate the photograph of the designed power dividers etched on Duroid 3003 and epoxy glass substrates, respectively. 


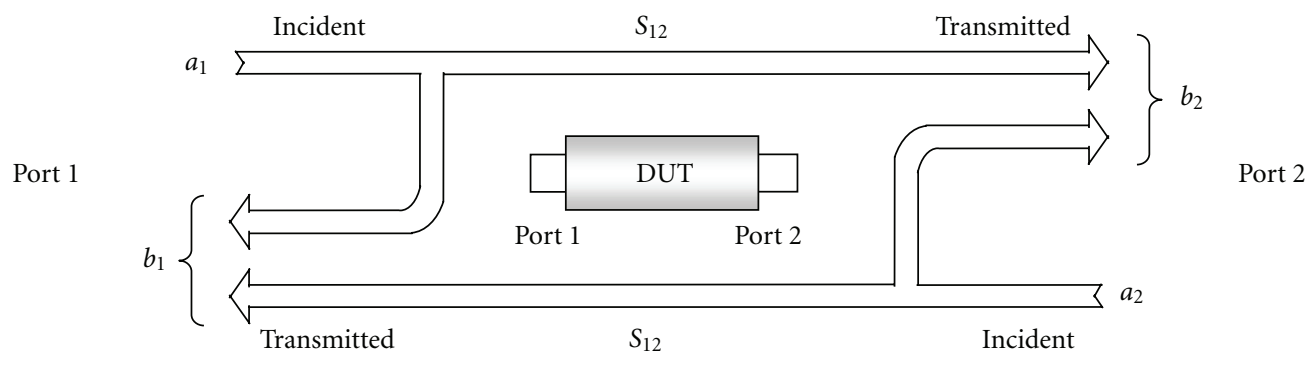

FIgURE 7: Block diagram of the experimental setup.

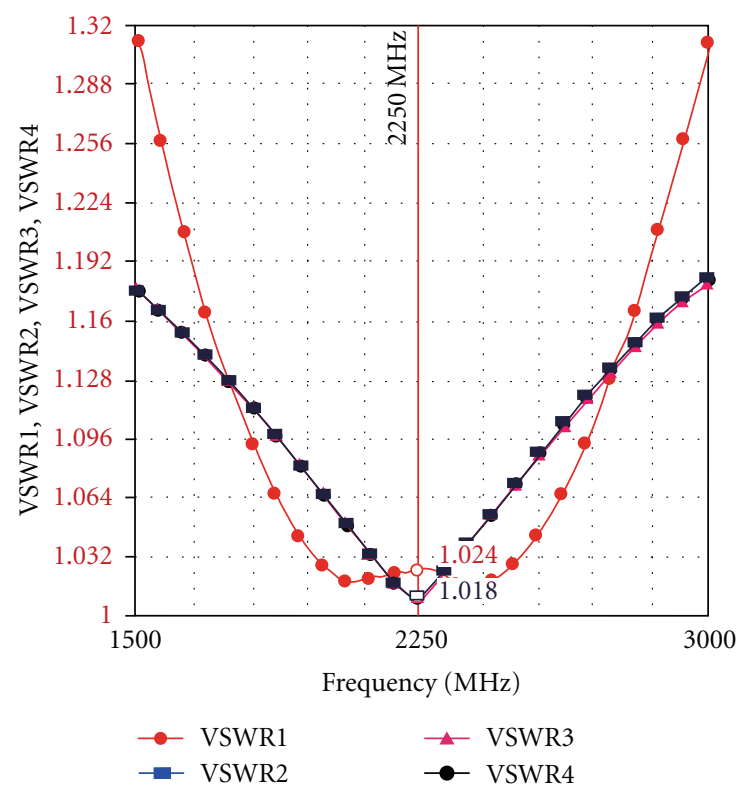

(a)

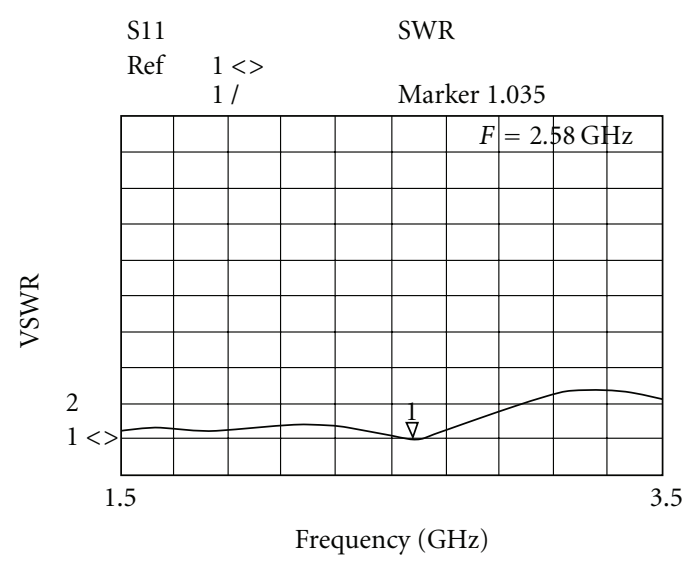

Start $1.5 \mathrm{GHz}$

(b)

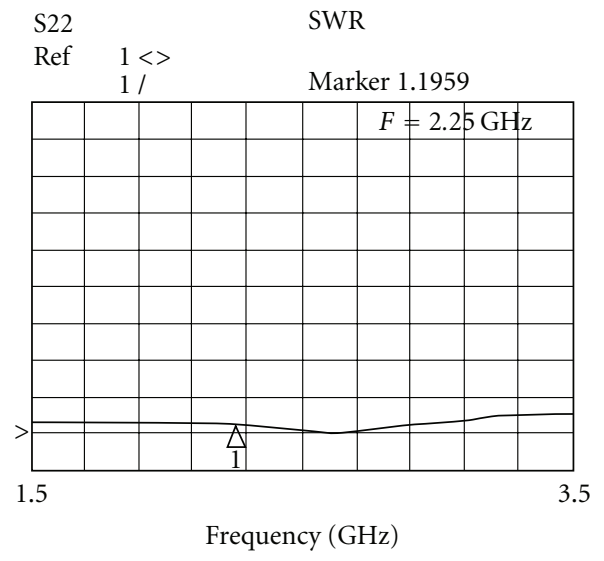

Start $1.5 \mathrm{GHz} \quad$ Stop $3.5 \mathrm{GHz}$

(c)

FIGURE 8: Response curves of 3-way 2-stage power divider printed on Duroid 3003 substrate. (a) Simulated input and output VSWR, (b) and (c) measured input and output VSWR, respectively. 


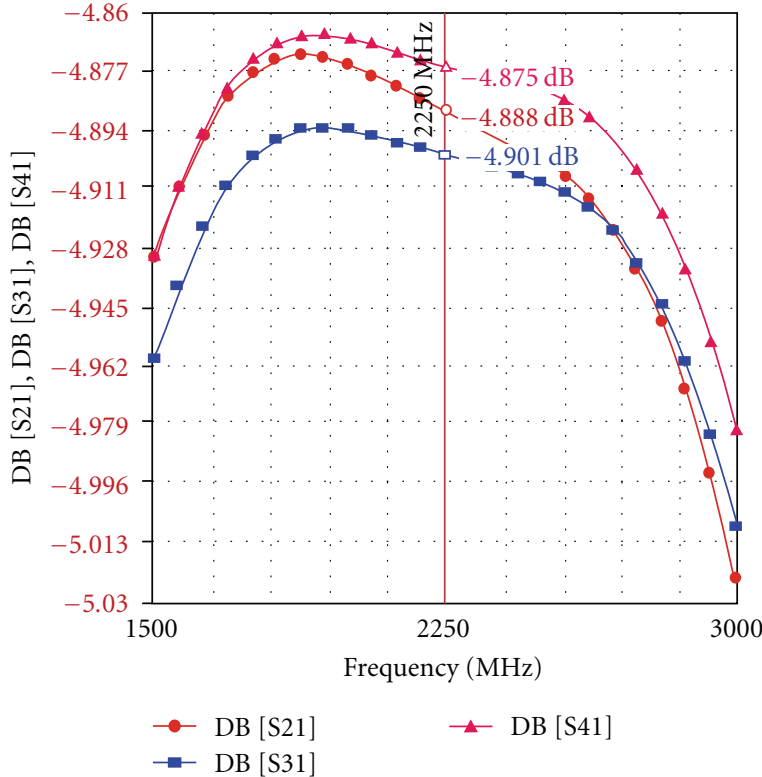

(a)

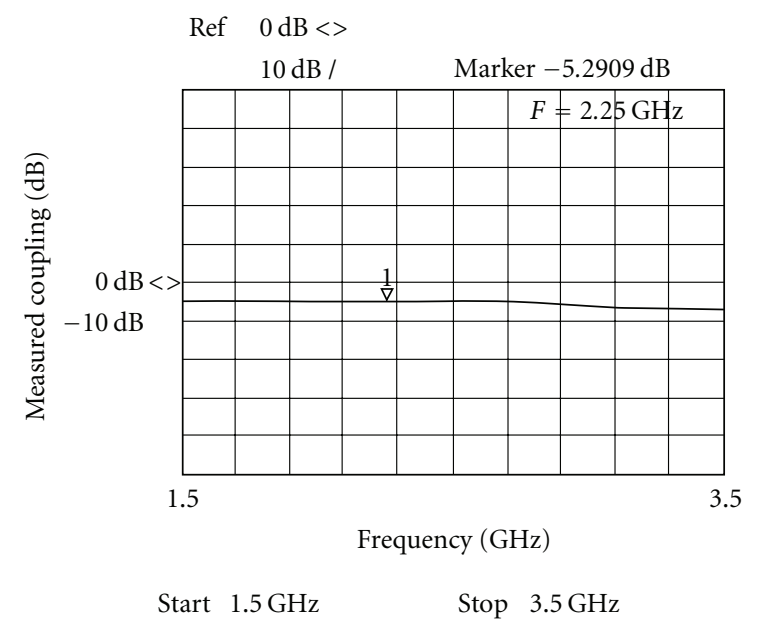

(b)

FIGURE 9: Response curves of 3-way 2-stage power divider printed on Duroid 3003 substrate. (a) Simulated coupling and (b) measured coupling.

2.2. Power Divider with Duroid 3010. The main difference between this substrate and the other is the high dielectric constant. The comparison is with the Duroid 3003 because it has approximately the same dissipation factor. A $50 \mathrm{ohms}$, $\lambda_{g} / 4$ line at midband frequency of $2.25 \mathrm{GHz}$ is $1.10 \mathrm{~mm}$ wide and $12.71 \mathrm{~mm}$ long. Following the same design procedure of power divider, the microstrip lines needed in the design are such thin that it is difficult to be fabricated; therefore the values of $Z_{0,1}$ and $Z_{0,2}$ are selected to give large dimensions $Z_{\text {in }}=25 \Omega, Z_{\text {out }}=19 \Omega, Z_{0,1}=53 \Omega, Z_{0,2}=26 \Omega, R_{1}=$ $22 \Omega, R_{2}=76 \Omega$.

An additional transformation matching line $\{B\}$ is inserted in the design to transform the impedance $\{A\}=25 \Omega$ to $50 \Omega$ line $\{C\}$ for matching purposes. Also an additional $30 \Omega$ stub is inserted to transform $19 \Omega$ output to the $50 \Omega$

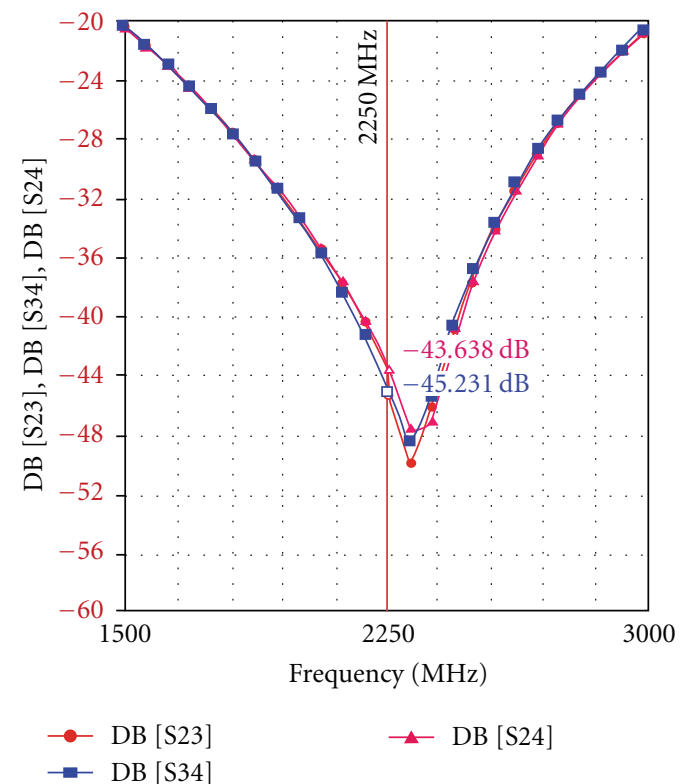

(a)

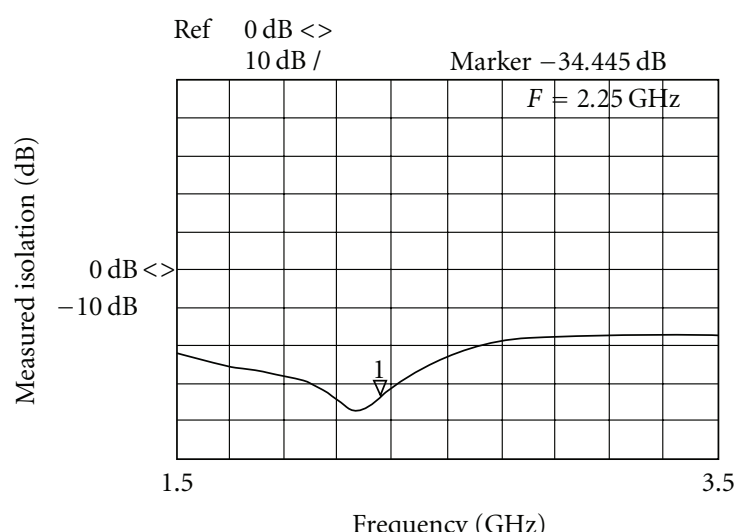

Start $1.5 \mathrm{GHz} \quad$ Stop $3.5 \mathrm{GHz}$

(b)

FIGURE 10: Response curves of 3-way 2-stage power divider printed on Duroid 3003 substrate. (a) Simulated isolation and (b) measured isolation.

line as shown in Figure 5. Figure 6 illustrates the photograph of the power divider etched on Duroid 3010 substrate.

\section{Experimental Setup}

The implemented designs of the studied microstrip power dividers are tested, and their characteristics are found by using the network analyzer $8510 \mathrm{HP}$. The network analyzer has two ports ( 1 and 2 ) that are connected, respectively, to the input and one of the outputs of the tested power divider, while the remaining outputs of the power divider are connected to $50 \Omega$ load for each. Voltage standing ratio VSWR, the coupling and the isolation between the power divider input and each output are measured by connecting the power divider input (representing port 1 of a device under test DUT 


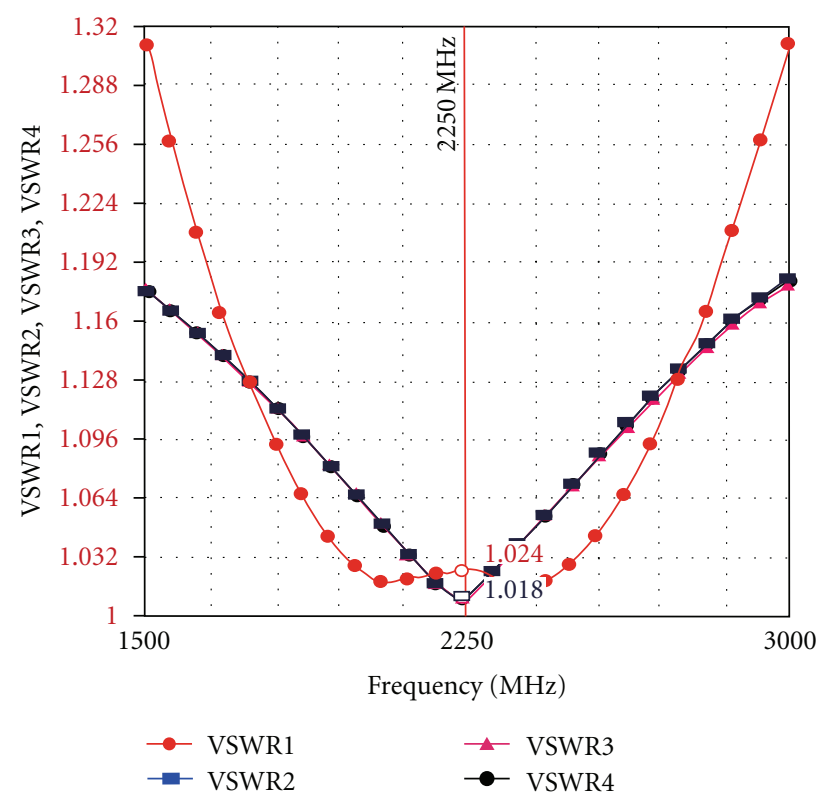

(a)

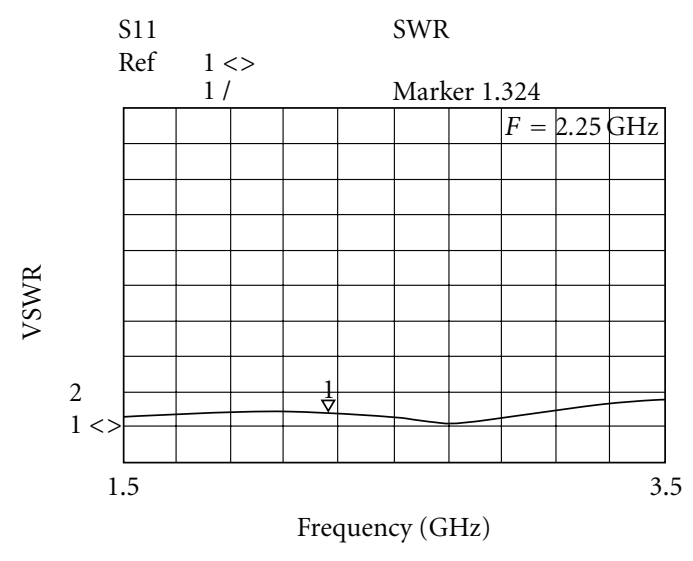

Start $1.5 \mathrm{GHz}$

(b)

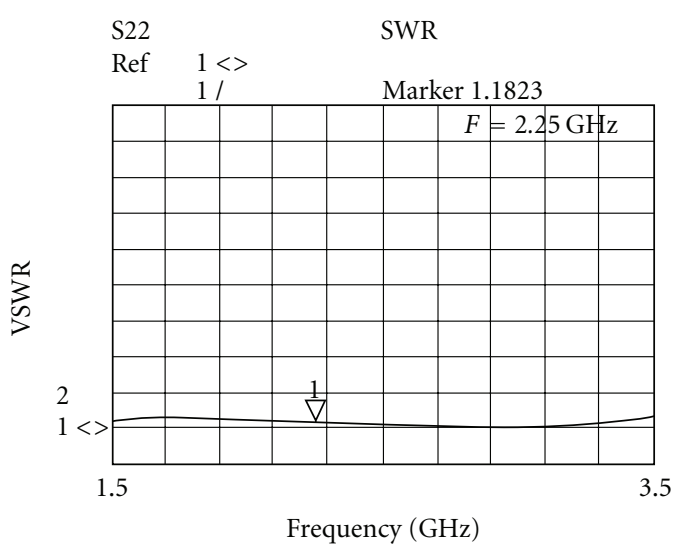

Start $1.5 \mathrm{GHz} \quad$ Stop $3.5 \mathrm{GHz}$

(c)

FIGURE 11: Response curves of 3-way 2-stage power divider printed on epoxy glass substrate. (a) Simulated input and output VSWR, (b) and (c) measured input and output VSWR, respectively.

as shown in Figure 7) to port 1 of the network analyzer $\left(a_{1}\right.$ and $b_{1}$ ), while the each power divider output representing port 2 of DUT is connected to port 2 of the network analyzer $\left(a_{2}\right.$ and $\left.b_{2}\right) . a_{1}$ and $b_{1}$ represent the incident and reflected or received voltage signals, respectively, at port 1 while $a_{2}$ and $b_{2}$ are the incident and reflected or received voltage signals, respectively, at port 2 of the network analyzer. Based on this setup, the following parameters are measured and the results are displayed directly on the analyzer [4].

(a) $S_{11}$ represents the forward reflection coefficient and $\mathrm{S}_{11}=\mathrm{b}_{1} / \mathrm{a}_{1}, \mathrm{a}_{2}=0$.

(b) Input VSWR represents the input match and $\operatorname{VSWR}=\left(1+\left|S_{11}\right|\right) /\left(1-\left|S_{11}\right|\right)$.

(c) $S_{22}$ represents the reverse reflection coefficient and $\mathrm{S}_{22}=\mathrm{b}_{2} / \mathrm{a}_{2}, \mathrm{a}_{1}=0$. (d) Output VSWR represents the output match and $\operatorname{VSWR}=\left(1+\left|S_{22}\right|\right) /\left(1-\left|S_{22}\right|\right)$.

(e) $S_{21}$ is the forward transmission coefficient that represents the coupling between the input and output ports and $S_{21}=b_{2} / a_{1}$ when $a_{2}=0$.

(f) $S_{12}$ is the reverse transmission coefficient that represents the coupling between the input and output ports and $S_{12}=b_{1} / a_{2}$ when $a_{1}=0$.

The above procedure is repeated for each tested output of the studied power divider taking into consideration that the calibration of the network analyzer ports should be made before the test beginning, regarding that the reference planes are taken at the power divider ports. 


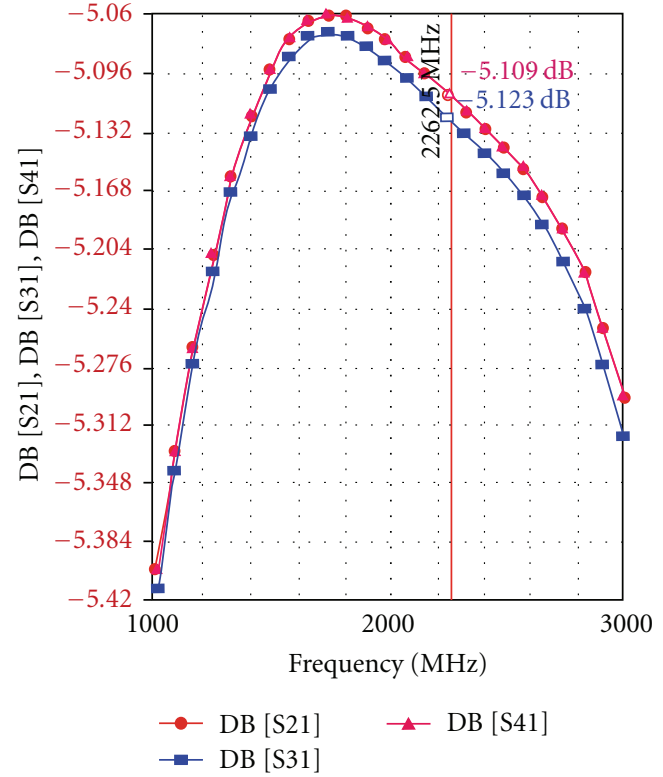

(a)

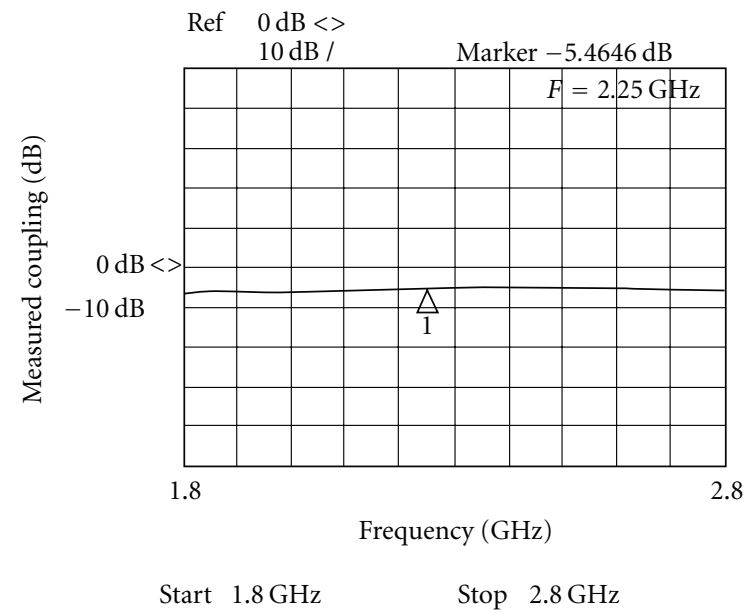

(b)

FIGURE 12: Response curves of 3-way 2-stage power divider printed on epoxy glass substrate. (a) Simulated coupling and (b) measured coupling.

\section{Results and Discussion}

By the aid of Genesys software package, the previous three designs of microstrip power dividers etched on the studied substrates are simulated and implemented. The characteristics of the implemented designs are determined using the experimental setup discussed in Section 3. Figure 8 shows the simulated and the measured VSWR on Duriod 3003.

The input VSWR is varying and less than $2: 1$ for frequency range $1.3-2.95 \mathrm{GHz}$, while the output VSWR is between 1 and 1.5 for the studied frequency range $1.5-3.5 \mathrm{GHz}$.

Figure 9 illustrates the coupling of the power divider printed on Duroid 3003.

The isolation parameter of power divider is shown in Figure 10. Agreement is found between the simulated and

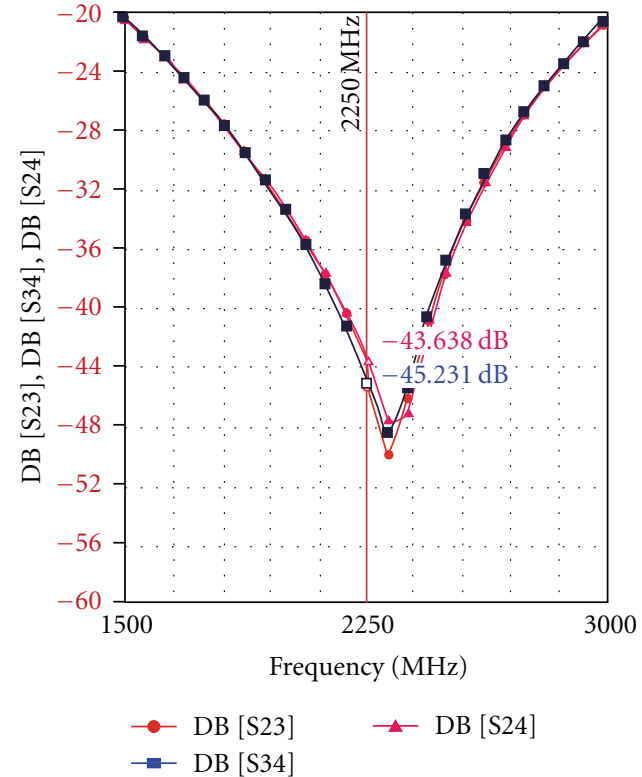

(a)

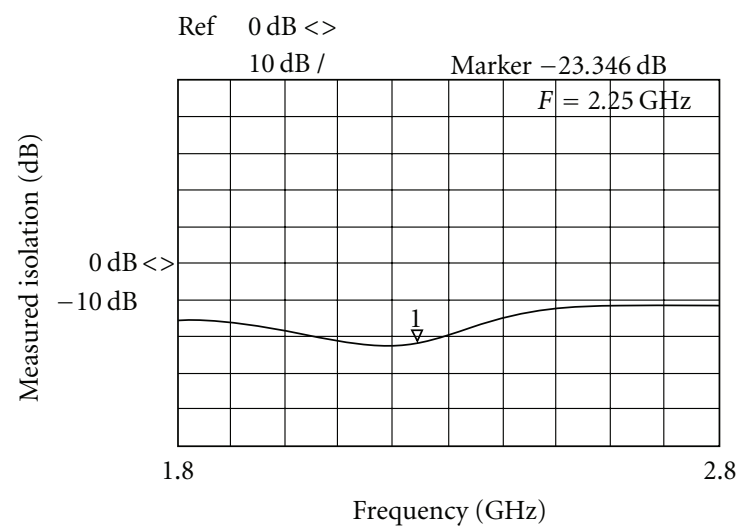

Start $1.8 \mathrm{GHz}$

Stop $2.8 \mathrm{GHz}$

(b)

FIGURE 13: Response curves of 3-way 2-stage power divider printed on epoxy glass substrate. (a) Simulated isolation and (b) measured isolation.

TABle 3: Comparison of the studied substrates at $2.25 \mathrm{GHz}$.

\begin{tabular}{lccc}
\hline & Duroid 3003 & Epoxy glass & Duroid 3010 \\
\hline Input VSWR & 1.4 & 1.3 & 1.14 \\
Output VSWR & 1.19 & 1.18 & 1.12 \\
Coupling (dB) & -5.3 & -5.4 & -5.38 \\
Isolation (dB) & -34 & -23.9 & -30 \\
\hline
\end{tabular}

measured results, in term of the shape of the curves on Duriod 3003.

The corresponding figures to those of the first prototype are shown in Figures 11, 12, and 13 for the power divider printed on epoxy glass substrate.

It can be seen that the increase in the split ratio indicates that there is more power lost compared to the first one and 


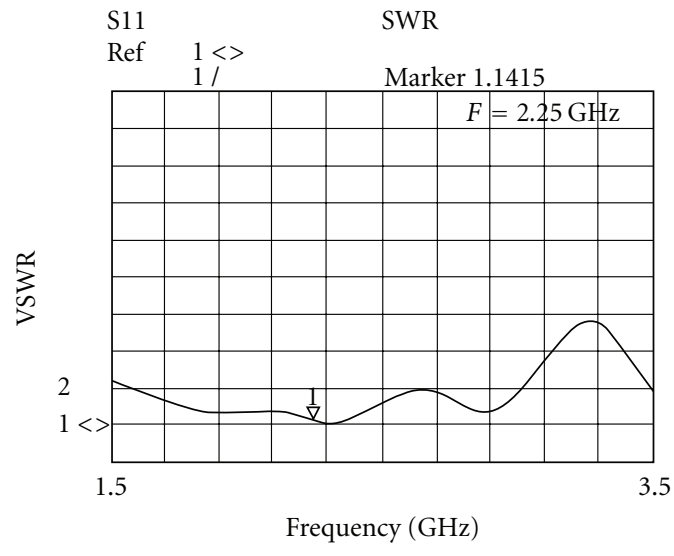

Start $1.5 \mathrm{GHz}$

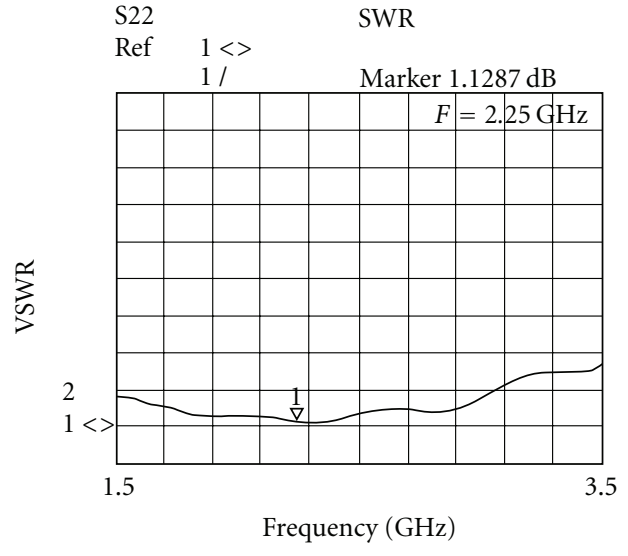

Start $1.5 \mathrm{GHz} \quad$ Stop $3.5 \mathrm{GHz}$

(b)

FIGURE 14: Response curves of 3-way 2-stage power divider printed on Duroid 3010 substrate. (a) Measured input VSWR and (b) measured output VSWR.

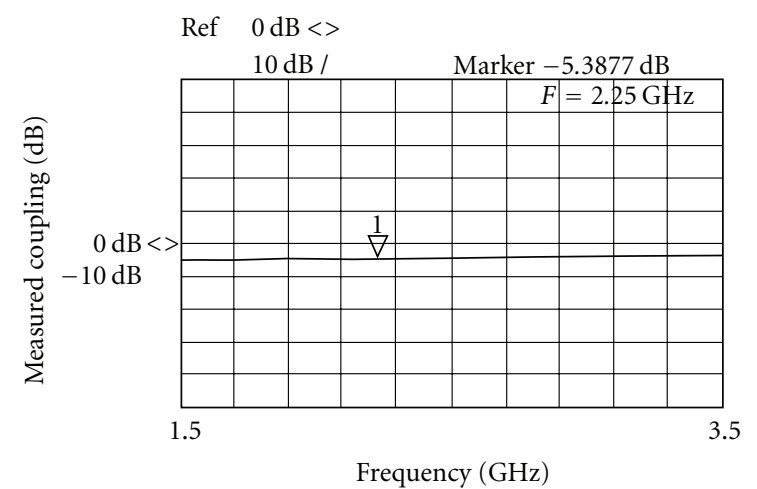

Start $1.5 \mathrm{GHz} \quad$ Stop $3.5 \mathrm{GHz}$

FIGURE 15: Measured coupling curve of 3-way 2-stage power divider printed on Duroid 3010 substrate.

is related to higher dissipation factor in the second substrate. Figures 14, 15, and 16 represent the simulated and measured VSWR, coupling and isolation of the third prototype etched on Duroid 3010, respectively.

It is clear that the measured coupling curves agree with the computed curve, and the coupling remains less than $-5.3 \mathrm{~dB}$ for different ports over the major part of the studied frequencies. The measured results are satisfactory.

It is seen that the most measured results presented in this study have a small shift in the center frequency, this is related to the etching that does not give the exact dimension of the lines. Table 3 compares the obtained results of the main parameters of the studied substrate materials.

\section{Conclusion}

The present study has introduced and discussed the effects of three substrate materials: Duroid 3003, epoxy glass, and Duroid 3010 on the characteristics of three-way twostage microstrip power dividers. The obtained results have

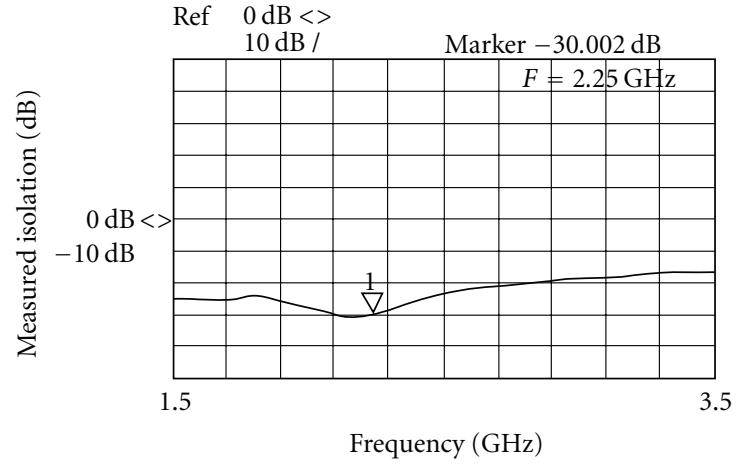

Start $1.5 \mathrm{GHz} \quad$ Stop $3.5 \mathrm{GHz}$

FIGURE 16: Measured isolation curve of 3-way 2-stage power divider printed on Duroid 3010 substrate.

indicated that the used Duroid 3010 has seemed better input and output VSWR than the others except the isolation in addition to that the used Duroid 3003 has indicated better characteristics than epoxy glass as observed in Table 3 . The availability of the substrate material, its price, the size required, the number of divider needed, and generally the cost are the main parameters to fulfill the design requirements.

\section{References}

[1] S. Shamsinejad, M. Soleimani, and N. Komjani, "Noval miniaturized wilkinson power divider for 3G mobile receivers," Progress In Electromagnetics Research Letters, vol. 3, pp. 9-16, 2008.

[2] S. M. Al-Ali and A. M. Al-Hindawi, "Effects of transformation lines on two-stage Wilkinson N-way power divider," in Proceedings of the International Conference on Communication, Computer \& Power (ICCCP '05), Muscat, Saltanat Uman, February 2005. 
[3] R. K. Hoffmann, Handbook of Microwave Integrated Circuits, Artech House, 1987.

[4] D. M. Pozar, Microwave Engineering, John Wiley, 3rd edition, 2005.

[5] T. C Edwards, Foundation for Microstrip Circuit Design, John Wiley, 1981.

[6] J. Lim, S. Lee, C. Soo, and J. Park, "Unqual Wilkinson power divider," IEEE Transactions on Microwave Theory and Techniques, vol. 11, no. 3, pp. 506-512, 2002.

[7] A. A. M. Saleh, "Planar electrically symmetric N-way hybrid power dividers/combiners," IEEE Transactions on Microwave Theory and Techniques, vol. 28, no. 6, pp. 555-563, 1980. 

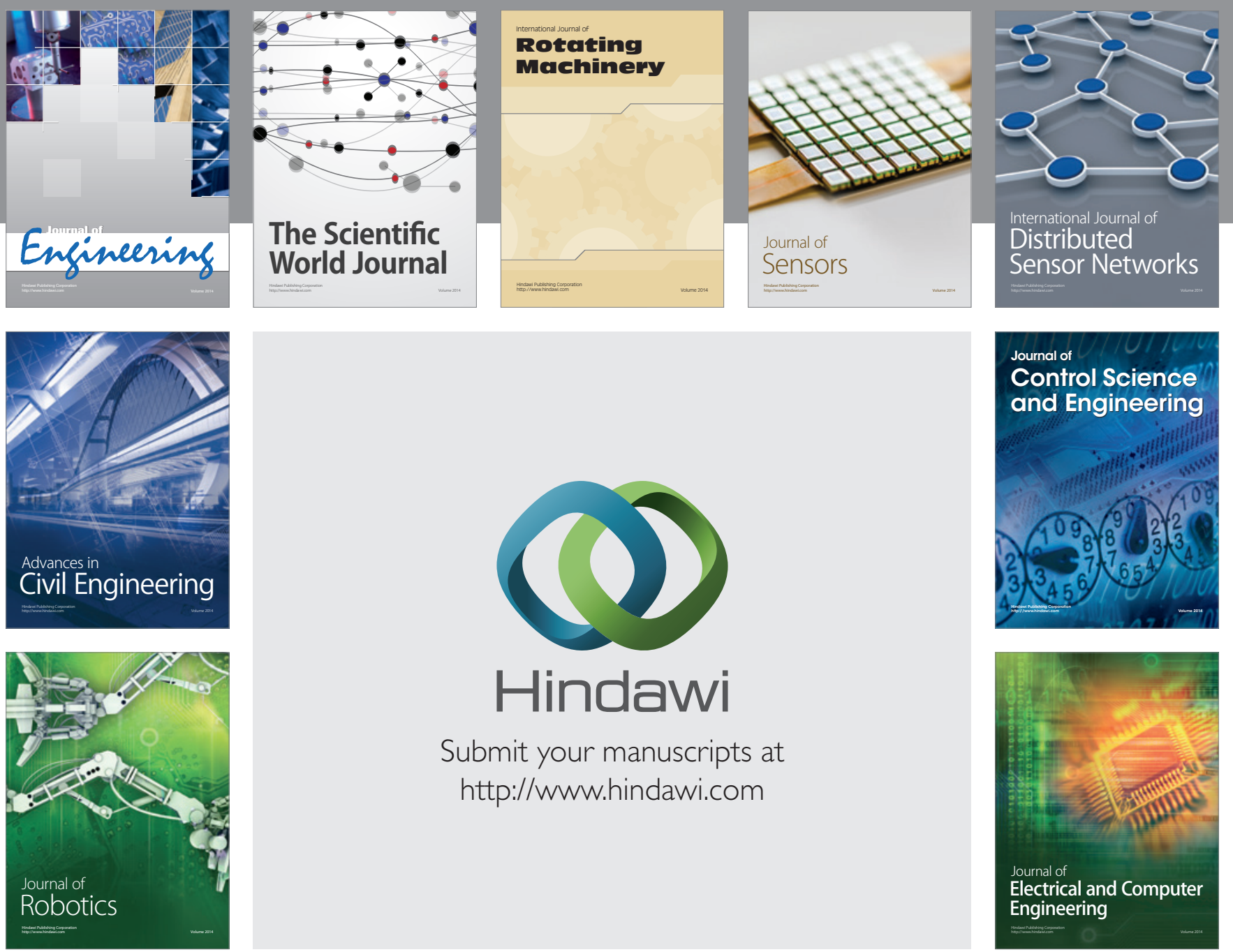

Submit your manuscripts at

http://www.hindawi.com
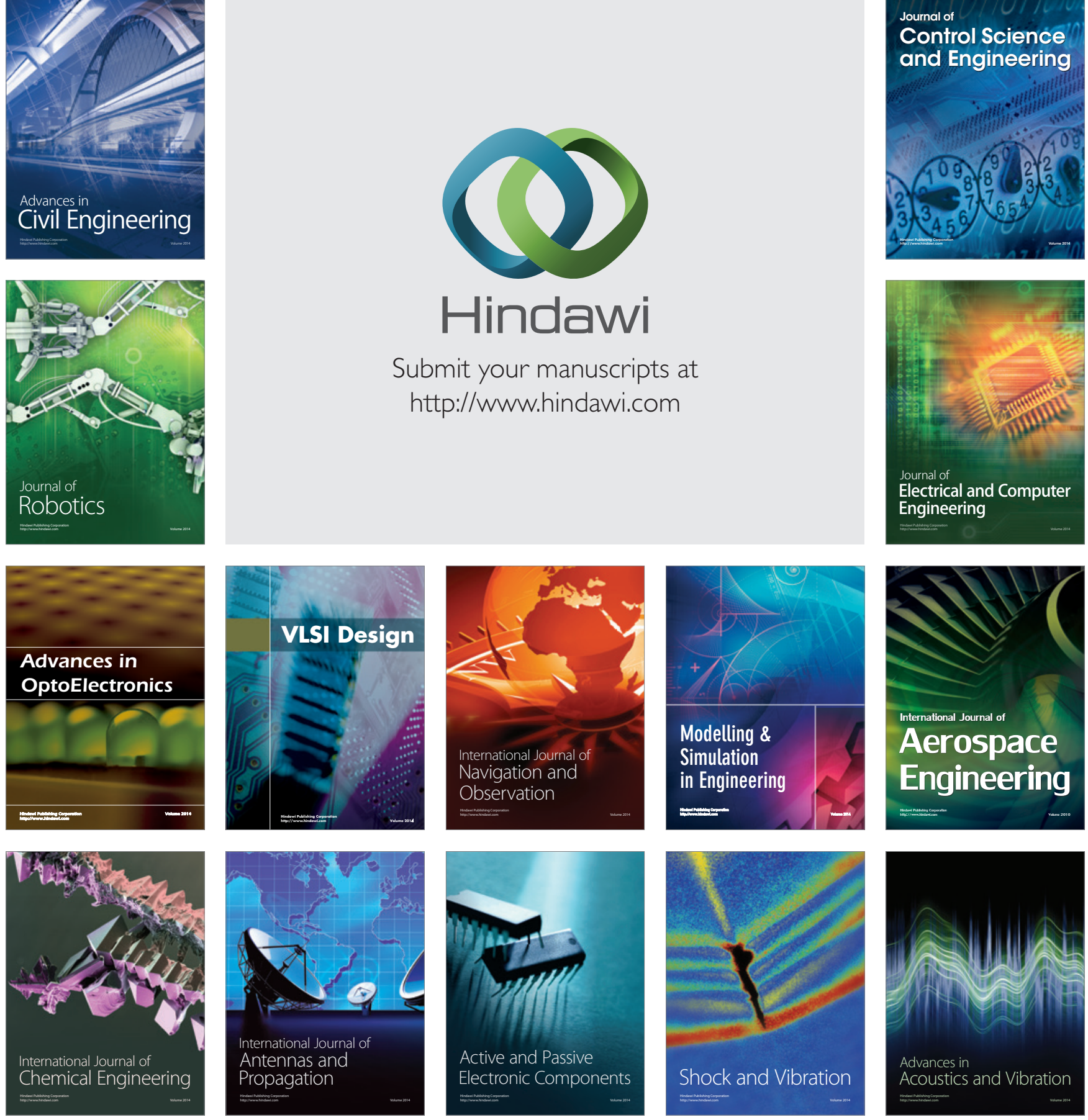